\title{
Evaluasi Tata Kelola Teknologi Informasi (TI) pada Pengembangan Aplikasi dan Data Menggunakan Framework COBIT 5 dan ISO/IEC 38500:2008 (Studi Kasus)
}

\author{
Suhartini Setia Ningsih ${ }^{1}$, Fitroh Fitroh ${ }^{2}$, Suci Ratnawati ${ }^{3}$
}

\begin{abstract}
Seksi Pengembangan Aplikasi dan Data (PAD) merupakan Sub Bagian Bidang E-Government DISKOMINFO Kabupaten Bogor yang memiliki tugas memantau kegiatan pengembangan sistem. Dalam pelaksanaannya seksi PAD memiliki permasalahan terkait kompetensi pegawai yang belum mencapai standar dalam pengembangan sistem (aplikasi) serta belum terlaksananya PERBUB No.11 Tahun 2015 tentang pelaksanaan dan pengembangan sistem. Oleh karena itu, peneliti melakukan evaluasi menggunakan framework COBIT 5 dan ISO/IEC 38500. Penelitian ini menggunakan Process Assessment Model (PAM) dengan skala Guttman untuk mengetahui hasil dan capability level. Fokus domain yang digunakan adalah EDM04 Ensure Resource Management dan MEA01 Monitor, Evaluate and Assess Performance and Conformance. Hasil dan capability level untuk kondisi saat ini (as is) adalah level 2 Managed Process dengan nilai 2,38. Sedangkan, untuk kondisi yang diharapkan (to be) berada pada level 3 Established Process dengan nilai 3,00 sehingga memiliki gap sebesar 0,62 yang kemudian dibuatkan rekomendasi perbaikan berdasarkan aktivitas yang dimiliki ISO/IEC 38500.
\end{abstract}

Keywords Tata Kelola Teknologi Informasi, COBIT 5, ISO/IEC 38500, Dinas Komunikasi dan Informatika Kabupaten Bogor

\section{Pendahuluan}

$\mathrm{S}$ eiring perkembangan teknologi informasi saat ini dapat dimanfaatkan suatu instansi atau lembaga dalam meningkatkan kinerja[1]. Untuk memenuhi kebutuhan akan informasi, maka banyak instansi atau lembaga berlomba-lomba dalam menerapkan sistem dan teknologi informasi yang dapat menyediakan informasi yang dibutuhkan secara cepat dan mudah serta dapat diakses kapanpun dan dimanapun[2].

Dalam membangun suatu sistem maka dibutuhkan tata kelola teknologi informasi (TI) untuk mendukung berbagai aktivitas dari suatu instansi atau lembaga dalam mencapai tujuannya[3, 4]. Tata kelola teknologi informasi yang baik dapat dilihat dari kondisi suatu instansi atau perusahaan dengan melakukan

Received: 20 Agustus 2019 ; Revised: 30 Agustus 2019 ; Accepted: 2 September 2019

S. S. Ningsih, Prodi Sistem Informasi, Universitas Islam Negeri Syarif Hidayatullah Jakarta, Indonesia (e-mail: suhartini.setianingsih14@mhs.uinjkt.ac.id). evaluasi untuk dapat mengetahui kesuksesan dari pelaksanaan teknologi informasi (TI) serta dapat diukur menggunakan metrik tata kelola teknologi informasi (TI) [5].

Dinas Komunikasi dan Informatika (DISKOMINFO) Kabupaten Bogor merupakan salah satu institusi atau lembaga pemerintahan yang bertugas mengawasi kegiatan pengembangan aplikasi dan data yang ada di lingkungan Kabupaten Bogor sesuai dengan aturan yang berlaku. Dalam menjalankan tugasnya DISKOMINFO Kabupaten Bogor berusaha menjalankan setiap program dan kegiatannya sesuai dengan perencanaan yang telah ditetapkan, akan tetapi terdapat beberapa kendala dimana berdasarkan hasil wawancara dengan Bapak Dendi Wahyudin S.Ip selaku Kepala Seksi Pengembangan Aplikasi dan Data, permasalahan yang dihadapi saat ini pada DISKOMINFO ialah kurangnya kompetensi pegawai dalam pembuatan atau pengembangan sistem (aplikasi) karena tidak adanya aturan baku terkait peningkatan kompetensi yang berupa pelatihan atau workshop terhadap pegawai DISKOMINFO Kabupaten Bogor sehingga belum tercapainya misi keempat dalam meningkatkan kualitas aparatur komunikasi dan informasi.

Selain itu, belum tercapainya peraturan bupati (PERBUB) No.11 Tahun 2015 tentang pelaksanaan dan pengembangan sistem (aplikasi) sehingga belum tercapainya target kinerja dalam koordinasi dan monitoring pengembangan sistem (aplikasi) pada lingkungan Kabupaten Bogor. Karena kurangnya koordinasi, DISKOMINFO merasa kesulitan dalam memonitor sistem yang berjalan sehingga belum terlaksananya peraturan yang berlaku. Dimana menurut Peraturan Bupati (PERBUB) Nomor 11 Tahun 2015 tentang Pelaksanaan dan Pengembangan E-Government di Lingkungan Pemerintah Kabupaten Bogor pasal 7 tentang penyediaan dan pengembangan aplikasi yang menyebutkan bahwa implementasi aplikasi baik umum maupun khusus harus dilakukan oleh SKPD dalam pelaksanaanya berkoordinasi dengan Dinas Komunikasi dan Informatika Kabupaten Bogor.

F. Fitroh, Prodi Sistem Informasi, Universitas Islam Negeri Syarif Hidayatullah Jakarta, Indonesia (e-mail: fitroh@uinjkt.ac.id).

S. Ratnawati, Prodi Sistem Informasi, UIN Syarif Hidayatullah Jakarta, Indonesia (e-mail: suci.ratnawati@uinjkt.ac.id). 
Koordinasi ini sangat dibutuhkan untuk dapat memonitor sistem yang ada. Selain permasalahan di atas, belum pernah dilakukannya evaluasi untuk tata kelola teknologi informasi pada DISKOMINFO dengan menggunakan framework COBIT 5.

Berdasarkan permasalahan di atas peneliti bermaksud melakukan penelitian untuk mengetahui capability level dan memberikan rekomentasi perbaikan terkait permasalahan yang sedang dihadapi pada DISKOMINFO Kabupaten Bogor khususnya pada pengembangan aplikasi dan data. Penelitian ini menggunakan framewok COBIT 5 dan ISO/IEC 38500. Pemilihan framework COBIT 5 pada penelitian ini didasari oleh karena COBIT 5 pada dasarnya merupakan framework yang terbuka untuk mengevaluasi apapun sehingga dapat digunakan sebagai kerangka dalam menentukan pemasalahan yang akan dievaluasi sedangkan ISO/IEC 38500 merupakan standar tata kelola yang menyediakan prinsip berdasarkan kerangka kerja dengan menyediakan dukungan terhadap penggunaan TI secara efektif, efisien dan tepat pada suatu organisasi dengan menggunakan enam (6) prinsip dan tiga (3) model utama sehingga dapat digunakan sebagai pendukung dalam memberikan rekomendasi dari hasil evaluasi yang akan dilakukan. Penggunaan framework COBIT 5 dan ISO/IEC 38500 dapat saling melengkapi untuk mencapai keselarasan teknologi informasi dan tujuan bisnis pada suatu organisasi[6]. Oleh karena itu, peneliti mengambil judul "Evaluasi Tata Kelola Teknologi Informasi (TI) Pada Pengembangan Aplikasi dan Data Menggunakan Framework COBIT 5 dan IEC/ISO 38500:2008 (Studi Kasus: Dinas Komunikasi dan Informatika (DISKOMINFO) Kabupaten Bogor.

\section{KAJIAN PENELITIAN}

Tata kelola teknologi informasi (TI) merupakan tanggung jawab dari dewan direksi dan manajemen eksekutif yang berupa kepemimpinan, stuktur organisasi dan kumpulan proses dalam menjamin teknologi informasi pada suatu instansi atau lembaga yang dapat mendukung tujuan dari instansi atau lembaga tersebut [7]. Tata kelola menjadi hal yang penting karena adanya perubahan peran TI yang mana manajemen level atas harus menangani perubahan peran efisien ke peran strategis, Banyaknya proyek TI yang gagal karena hanya ditangani oleh teknisi, keputusan TI yang bersifat ad hoc dan tidak terencana baik oleh dewan direksi, TI merupakan pendorong utama dalam transformasi bisnis bagi suatu organisasi dalam mencapai visi, misi dan tujuan, selain itu, suksesnya TI harus terukur melalui metriks tata kelola TI [8].

Evaluasi tata kelola teknologi informasi merupakan proses pengukuran terhadap nilai dari teknologi informasi (TI) pada suatu instansi atau perusahaan baik dalam pembangunan hingga pengelolaannya dalam mendukung tujuan dari instansi atau perusahaan dan dapat dipertanggungjawabkan oleh dewan direksi dan manajemen eksekutif [5]. Dalam mengevaluasi tata kelola teknologi informasi pada suatu organisasi dibutuhkan framework yang tepat agar hasil pengukuran dapat dijadikan acuan untuk pembuatan rekomendasi yang lebih baik. Salah satu framework yang dapat digunakan dalam mengevaluasi tata kelola TI adalah Control Objective for Information and Related
Technology (COBIT) dan International Organization for Standardization (ISO) dan International Electrotechnical Commission (IEC) ISO/IEC 38500:2008.

COBIT 5 merupakan panduan atau sekumpulan dokumentasi untuk mengimplementasikan IT Governance, kerangka kerja ini dapat membantu auditor, manajemen dan pengguna (user) dalam menjembatani kebutuhan bisnis, resiko bisnis dan permasalahan teknis. Selain itu, COBIT memiliki spektrum proses TI yang lebih luas dan mendetail dibandingkan dengan lainnya[9]. Sedangkan ISO/IEC 38500:2008 merupakan standar tata kelola yang menyediakan prinsip berdasarkan kerangka kerja dengan menyediakan dukungan terhadap penggunaan TI secara efektif, efisien dan tepat pada suatu organisasi. Selain itu, prinsip pada ISO/IEC 38500:2008 lebih dapat disesuaikan untuk mendukung pengambilan keputusan, dimana tiap prinsip mengarah pada apa yang harusnya terjadi, bukan pada bagaimana, kapan dan siapa prinsip akan diimplementasikan[10].

Menurut Blanchard dan Thacker [11] kompetensi adalah sekelompok pengetahuan terkait keterampilan dan sikap yang membedakan pegawai dari yang berkinerja tinggi dan berkinerja rata-rata. Menurut Perry [12] kompetensi adalah sekelompok pengetahuan terkait sikap dan keterampilan yang mempengaruhi sebagian besar pekerjaan seseorang yang berkorelasi dengan kinerja di tempat kerja sehingga dapat diukur terhadap standar yang diterima dengan baik serta dapat ditingkatkan melalui pelatihan dan pengembangan.

Monitor merupakan memantau kepatuhan dan kesesuaian TI melalui praktik pelaporan dan audit yang tepat, memastikan bahwa tinjauan tepat waktu, komprehensif, dan sesuai untuk evaluasi tingkat kepuasan bisnis [10]. Sedangkan koordinasi merupakan serangkaian usaha yang dilakukan secara teratur untuk menyediakan jumlah dan waktu yang tepat dalam mengarahkan pelaksanaan suatu kegiatan agar menghasilkan tindakan yang seragam dan harmonis pada tujuan yang telah ditetapkan[13].

Prosess Assessment Model (PAM) merupakan model yang digunakan untuk penilaian kemampuan proses teknologi informasi pada suatu organisasi atau perusahaan [14]. Prosess Assessment Model (PAM) memiliki tujuh assessment process activities (langkah-langkah aktivitas) yang dilakukan untuk proses penilaian capability level yang teridiri dari[14]:

A. Initiation

B. Planning the Assessment

C. Briefing

D. Data Collection

E. Data Validation

F. Process Attribute Level

G. Reporting the Result

Skala perhitungan yang digunakan pada penelitian ini ialah skala Guttman (skala kumulatif), skala ini besifat undimensional yang mengukur satu dimensi saja dari satu variable yang multi dimensi. Skala Guttman disebut juga metode scalogram atau analisa skala (scale analysis) yang baik untuk meyakinkan peneliti tentang kesatuan dimensi dari sikap atau sifat yang diteliti, yang disebut (universe of content) atau (universe of attributte)[15] 


\section{Metode Penelitian}

Berikut metode penelitian yang menggunakan Process Assessment Model (PAM) dapat dilihat pada gambar 1:

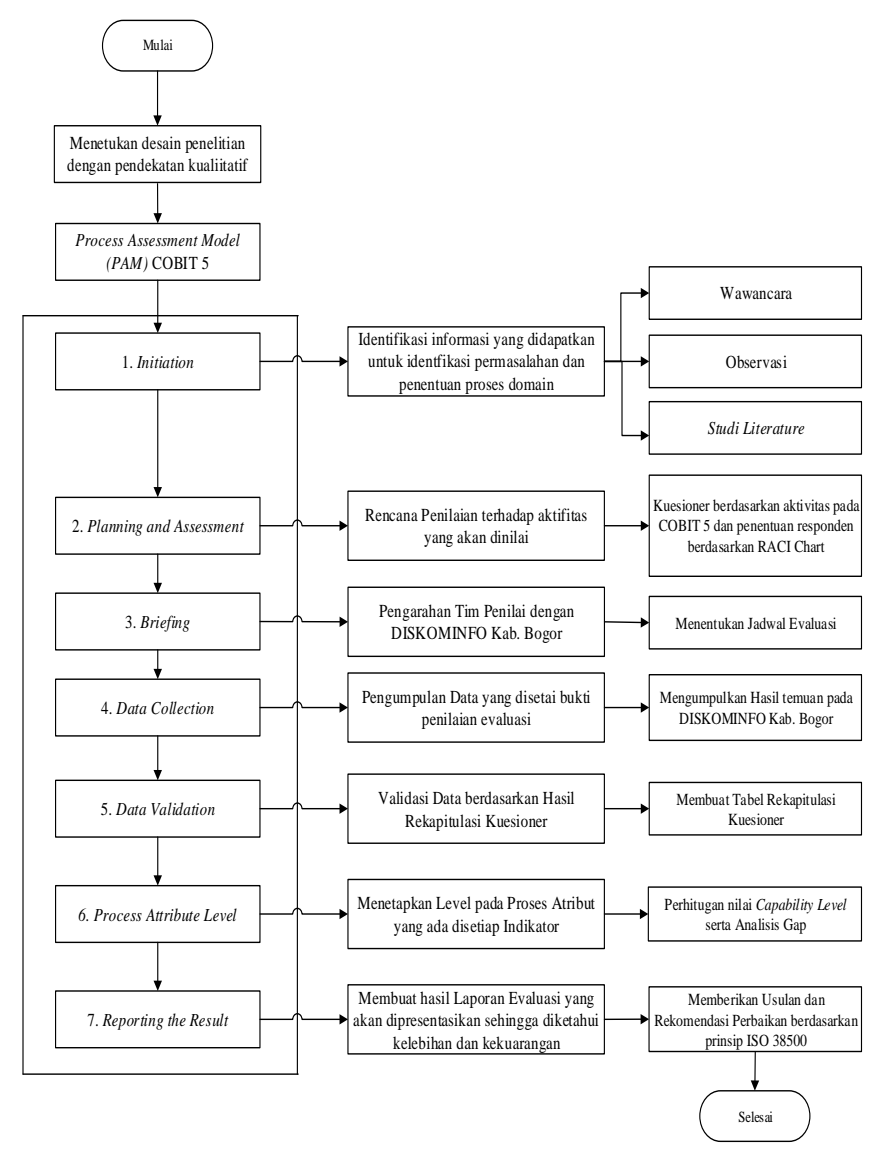

Gambar 1. Kerangka Berfikir

IV. HASIL

\section{A. Initiation}

Initiation merupakan tahap pertama yang dilakukan untuk menjelaskan hasil identifikasi dari beberapa informasi yang didapatkan. Pada tahap ini dilakukan wawancara dengan kepala seksi pengembangan aplikasi dan data Bapak Dendi Wahyudin S.Ip pada 30 Juli 2018 dan 6 Agustus 2018. Kemudian dilakukan observasi langsung di kantor DISKOMINFO Kabupaten Bogor, memberikan kuesioner dan studi literatur terkait penelitian sejenis. Berdasarkan permasalahan yang diketahui melalui wawancara dengan salah satu pegawai yang bersangkutan, maka ditetapkan dua enterprise goals yakni Skill and Motivated People dan IT compliance with internal policies. Dari kedua enterprise goals yang ditetapkan maka dipilih dua IT related goals pada dimensi learning and growth dan internal yakni Competent and Motivated Business and IT Personel dan IT compliance with internal policies. Dari dua IT related goals yang dipilih didapatkan domain COBIT yakni EDM04 dan MEA01.

\section{B. Planning the Assessment}

Pada tahap ini dilakukan pembuatan kuesioner dengan aktivitas yang dimiliki domain proses EDM04 Ensure Resource ptimisation dan MEA01 Monitor Evaluate and Assess Performance and Conformance. Sedangkan, metode perhitungan kuesioner menggunakan perhitungan Guttman. Penentuan responden dengan menggunakan teknik purposive sampling sesuai dengan RACI Chart pada domain proses yang dipilih.

\section{Briefing}

Pengisian kuesioner dilakukan pada tanggal 14-19 Desember 2018, pengumpulan data dilakukan pada tanggal 19 Desember 2018 sampai 11 Januari 2019, rekapitulasi hasil kuesioner pada tanggal 11-18 Januari 2019, Analisis data pada tanggal 21 Januari sampai 10 April 2019, pelaporan hasil penilaian 25 Januari 2019 sampai 10 April 2019.

\section{Data Collection}

Tahap ini bertujuan untuk mendapatkan bukti penilaian evaluasi pada aktivitas proses yang dilakukan. Berikut merupakan temuan pada EDM04 Ensure Resource Optimization, yaitu:

1) EDM04.01 Ensure Resource Management

Pengalokasian sumber daya yang belum maksimal karena keterbatasannya kompetensi yang dimiliki oleh pegawai sehingga ada posisi yang kurang sesuai dengan latar belakang pendidikan yang dimiliki, strategi sumber daya TI terkait pengembangan aplikasi yang hanya diatur secara umum dan belum adanya aturan baku yang spesifik terkait kapasaitas dan batasan terhadap sumber daya TI terkait pengembangan sistem, kegiatan pelatihan yang tidak menyeluruh karena hanya diperuntukan kepada pegawai yang berstatus PNS sedangkan pegawai yang berstatus NonPNS lebih mendominasi, kegiatan pelatihan yang belum terjadwal dan direncanakan dengan baik dan keterlambatan dalam memberikan hasil laporan kinerja yang telah dilakukan.

\section{2) EDM04.02 Direct Resource Management}

Kurangnya pemeliharaan terhadap sumber daya yang dimiliki sehingga pada proses ini diperlukannya pengelolaan dan pengarahan dalam menjaga sumber daya (aset) yang dimiliki oleh DISKOMINFO sesuai dengan tanggung jawab yang telah ditetapkan, dilakukannya komunikasi dan dorongan terhadap penerapan rencana kerja yang ditetapkan, akan tetapi pada pelaksanaannya belum dilakukan secara maksimal pada Seksi Pengembangan Aplikasi dan Data DISKOMINFO Kabupaten Bogor, selain itu, tanggung jawab yang diberikan melalui tugas dan fungsi yang telah diatur oleh Peraturan Bupati No 57 Tahun 2016 belum dilakukan secara utuh karena aturan yang dibuat secara umum dan tidak spesifik baik terkait ruang lingkup dan batasan DISKOMINFO Kabupaten Bogor dalam mengembangkan aplikasi di lingkungan Kabupaten Bogor.

\section{3) EDM04.03 Monitor Resource Management}

Pengawasan terkait target kinerja dilakukan secara umum agar memastikan target dilaksanakan, akan tetapi dalam 
Pengawasan terhadap alokasi penempatan sumber daya belum dilakukan secara maksimal karena belum ada aturan yang mengatur secara khusus terkait bagaimana pengawasan yang upaya menangani masalah yang muncul masih dilakukan secara base on case (diperbaiki pada saat masalah muncul) tanpa adanya pengawasan yang berkelanjutan dalam penanganannya, sehingga analisa penyebab dan upaya penanganan yang dilakukan tidak terdokumentasi dengan baik.

Kurangnya pencatatan pada permasalahan yang ada dan tindakan perbaikan yang dilakukan. Kegiatan ini berguna untuk mengatasi permasalahan karena ada pedomannya dalam mengatasi permasalahan.

Berikut merupakan temuan pada MEA01 Monitor Evaluation and Assess Performance and Conformance, yaitu:

\section{1) MEA01.01 Establish a Monitoring Approach}

Identifikasi stakeholder (manajemen tingkat atas) dan keterlibatannya dalam proses pengembangan aplikasi dilakukan sesuai dengan prosedur yang berlaku akan tetapi informasi terkait prosedur pengembangan aplikasi masih kurang pada DISKOMINFO Kabupaten Bogor. Kemudian, penempatan DISKOMINFO Kabupaten Bogor sebagai konsultan IT bagi SKPD yang akan mengembangkan aplikasi pada lingkungan Kabupaten Bogor yang masih belum dipahami oleh SKPD lainnya sehingga koordinasi yang dilakukan terbatas hanya pada pemberitahuan aplikasi apa yang telah dibuat dan digunakan agar untuk dijadikan laporan. selain itu, kurangnya pendekatan dan koordinasi antar dinas dalam kegiatan pengembangan aplikasi dan data sehingga adanya kesenjangan informasi yang diberikan.

2) MEA01.02 Set Performance and Conformance targets.

Pada proses ini kegiatan perencanaan terhadap target kinerja telah teridentifikasi akan tetapi dalam pelaksanaannya belum dilakukan dengan baik dimana publikasi informasi terkait pengembangan aplikasi kepada SKPD yang masih belum maksimal sehingga banyak yang belum mengetahui fungsi dari DISKOMINFO dalam mengembangkan aplikasi pada lingkungan Kabupaten Bogor. Kemudian, Belum dilakukannya identifikasi resiko terhadap kegiatan pengembangan aplikasi yang telah dilakukan. Kemudian, evaluasi yang dilakukan terbatas pada rapat kegiatan yang direncanakan secara umum tidak spesifik terkait pengembangan aplikasi yang telah dilakukan untuk memberikan penilaian terhadap proses kegiatan dari pengembangan aplikasi pada DISKOMINFO Kabupaten Bogor.

3) MEA01.03 Collect and Process Performance and Conformance Data

Sedikitnya informasi yang diperoleh dalam kegaitan pengembangan aplikasi dan data perlu diperhatikan agar mendapatkan hasil penilaian yang baik. Informasi yang dikumpulkan terkait pengembangan aplikasi masih berlum dilakukan secara utuh, dimana terbatas pada SKPD yang melaporkan kegiatan pengembangan aplikasinya secara mandiri pada DISKOMINFO sehingga SKPD yang tidak melaporkan kegiatan pengembangan aplikasinya yang dilakukan secara mandiri tanpa koordinasi dengan DISKOMINFO tidak tercatat dengan baik.

4) MEA01.04 Analysy and Report Performance

Belum adanya dokumentasi terhadap analisa penyebab terjadinya penyimpangan dan bagaimana tindakan perbaikannya sehingga jika terjadi permasalahan yang sama tidak ada panduan untuk menanganinya secara tertulis pada DISKOMINFO Kabupaten Bogor. Kemudian, kurangnya analisa penyebab penyimpangan terhadap kegiatan pengembangan aplikasi. Mulai dari menetapkan tindakan tanggung jawab terhadap tindak lanjut permasalahan yang ada pada DISKOMINFO. Selain itu, kurangnya apresiasi terhadap pencapaian target kinerja ke sistem kompensasi imbalan organisasi pada DISKOMINFO Kabupaten Bogor dan kurangnya koordinasi terhadap kegiatan pengembangan aplikasi sehingga laporan yang disajikan kurang relevan.

5) MEA01.05 Ensure the Implementation of Corrective Actions

Tindakan perbaikan doing by case yang diterapkan sangat beresiko jika terjadi permasalahan yang besar karena akan sulit ditangani bahkan memerlukan waktu.

\section{E. Data Validation}

Berdasarkan hasil jawaban responden dari kuesioner yang diberikan dengan skala Guttman yang kemudian diproses dengan metode perhitungan yang ada pada Guttman. Berikut merupakan hasil penilaian capability level dari EDM04 Ensure Resource Management dan MEA01 Monitor Evaluation and Assess Performance dan Conformance yang diperoleh dari rekapitulasi jawaban responden yang telah ditentukan oleh RACI Chart. 
Applied Information Systems and Management (AISM)

Volume 2, (2) 2019, hal 81-90,

P-ISSN: 2621-2536 ;E-ISSN: 2621-2544

Tabel 1.

Hasil Capability Level EDM04

\begin{tabular}{|c|c|c|c|c|c|c|c|c|c|c|}
\hline Domain & Responden & Level 0 & Level 1 & Level 2 & Level 3 & Level 4 & Level 5 & $\begin{array}{c}\text { Capability } \\
\text { Level }\end{array}$ & $\begin{array}{c}\text { Expected } \\
\text { Level }\end{array}$ & $\begin{array}{c}\text { Maximum } \\
\text { Level }\end{array}$ \\
\hline & $\mathrm{R} 1$ & 0,00 & 0,24 & 0,59 & 0,88 & 0,00 & 0,29 & 2,00 & 3,00 & 5,00 \\
\hline EDM04.01 & $\mathrm{R} 2$ & 0,00 & 0,15 & 0,31 & 0,46 & 0,62 & 0,38 & 1,92 & 3,00 & 5,00 \\
\hline \multicolumn{8}{|c|}{ Rata-rata Capability Level } & 1,96 & 3,00 & 5,00 \\
\hline & $\mathrm{R} 1$ & 0,00 & 0,31 & 0,63 & 0,94 & 0,00 & 0,31 & 2,19 & 3,00 & 5,00 \\
\hline EDM04.02 & $\mathrm{R} 2$ & 0,00 & 0,15 & 0,30 & 0,60 & 0,80 & 1,00 & 2,85 & 3,00 & 5,00 \\
\hline \multicolumn{8}{|c|}{ Rata-rata Capability Level } & 2,52 & 3,00 & 5,00 \\
\hline & $\mathrm{R} 1$ & 0,00 & 0,33 & 0,67 & 1,00 & 0,00 & 0,00 & 2,00 & 3,00 & 5,00 \\
\hline EDM04.03 & $\mathrm{R} 2$ & 0,00 & 0,43 & 0,57 & 0,43 & 0,00 & 0,71 & 2,14 & 3,00 & 5,00 \\
\hline \multicolumn{8}{|c|}{ Rata-rata Capability Level } & 2,07 & 3,00 & 5,00 \\
\hline
\end{tabular}

Tabel 2.

Hasil Capability Level MEA01

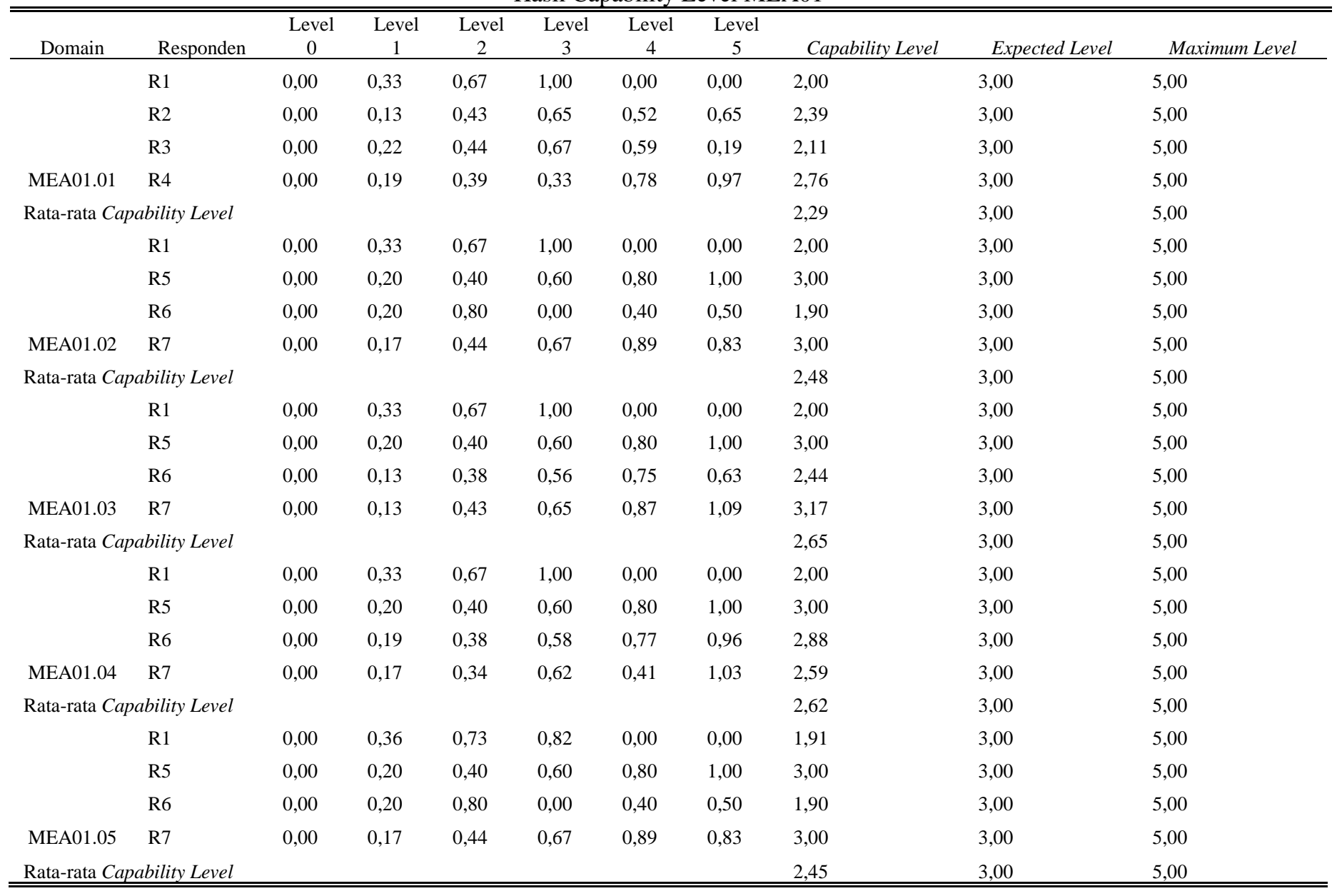




\section{F. Process Attribute Level}

Process attribute level dilakukan dengan mengecek setiap indikator persyaratan pada aktivitas EDM04 dan MEA01yang harus dipenuhi pada masing-masing level berdasarkan ketentuan dari kategori dan hasil penilaian setiap levelnya (level 0 sampai level 5). Berikut merupakan kategori penilaian pada setiap level domain proses EDM04 Ensure Resource Optimization dan MEA01 Monitor Evaluate and Assess Performance and Conformance:

1) EDM04 Ensure Resource Management

Berikut merupakan tabel process attribute level pada level 2 Manage Process:

Tabel 3.

\begin{tabular}{|c|c|c|c|c|}
\hline \multicolumn{5}{|c|}{ GWP \& Performance Management } \\
\hline & Process Attribute 2. & Perfo & rance $M$ & gement \\
\hline No & Goal Work Product & Ya & Tidak & Bukti \\
\hline 1 & $\begin{array}{l}\text { Identifikasi kebutuhan } \\
\text { sumber daya }\end{array}$ & $\checkmark$ & & $\begin{array}{l}\text { Tugas, dan fungsi } \\
\text { serta tata kerja } \\
\text { DISKOMINFO }\end{array}$ \\
\hline 2 & $\begin{array}{l}\text { Identifikasi strategi } \\
\text { alokasi sumber daya }\end{array}$ & $\checkmark$ & & Struktur Organisasi \\
\hline 3 & $\begin{array}{l}\text { Identifikasi kriteria } \\
\text { kompetensi sumber } \\
\text { daya }\end{array}$ & $\checkmark$ & & $\begin{array}{l}\text { Data profile } \\
\text { pegawai }\end{array}$ \\
\hline 4 & $\begin{array}{l}\text { Identifikasi } \\
\text { permasalahan pada } \\
\text { manajemen sumber } \\
\text { daya }\end{array}$ & $\checkmark$ & & LAKIP \\
\hline 5 & $\begin{array}{l}\text { Identifikasi resiko } \\
\text { tindakan } \\
\text { penyimpangan }\end{array}$ & & $\checkmark$ & - \\
\hline
\end{tabular}

Pada Tabel 3. diketahui bahwa untuk memastikan sumber daya dan TI dialokasikan secara optimal memiliki semua dokumen yang dibutuhkan. Akan tetapi identifikasi resiko tindakan penyimpangann belum dilakukan karena penanganan doing by case yang biasa dilakukan.

Tabel 4.

GWP \& Work Product Management

\begin{tabular}{|c|c|c|c|c|}
\hline \multicolumn{5}{|c|}{ Process Attribute 2.2 Work Product Management } \\
\hline No & Goal Work Product & $\mathrm{Ya}$ & Tidak & Bukti \\
\hline 1 & Kriteria hasil kinerja & $\checkmark$ & & LAKIP \\
\hline 2 & $\begin{array}{l}\text { Komunikasi dan } \\
\text { arahan manajemen } \\
\text { sumber daya }\end{array}$ & $\checkmark$ & & $\begin{array}{l}\text { Rapat } \\
\text { Koordinasi }\end{array}$ \\
\hline 3 & $\begin{array}{l}\text { Pemanfaatan dan } \\
\text { penerapan strategi } \\
\text { manajemen sumber } \\
\text { daya }\end{array}$ & $\checkmark$ & & $\begin{array}{l}\text { Rencana } \\
\text { Kegiatan }\end{array}$ \\
\hline 4 & $\begin{array}{l}\text { Alokasi kompetensi } \\
\text { sumber daya }\end{array}$ & & $\checkmark$ & - \\
\hline 5 & $\begin{array}{l}\text { Rencana manajemen } \\
\text { resiko terhadap } \\
\text { tindakan } \\
\text { penyimpangan }\end{array}$ & & $\checkmark$ & - \\
\hline
\end{tabular}

Pada Tabel 4. terdapat dokumen yang tidak terpenuhi untuk alokasi kompetensi sumber daya dikarenakan banyak pegawai yang tidak memiliki latar belakang pendidikan di bidang TI sehingga pengalokasian untuk kompetensi sumber daya belum tercapai. Serta rencana manajemen resiko terhadap tindakan penyimpangan dikarenakan penanganan hanya dilakukan ketika penyimpangan terjadi pada saat itu.

Berikut merupakan tabel process attribute level pada level 3 Established Process:

Tabel 5.

GWP \& Process Definition

\begin{tabular}{llll}
\hline \hline \multicolumn{4}{c}{ Process Attribute 3.1 Process Definition } \\
\hline No & $\begin{array}{l}\text { Goal Work Product } \\
\text { Tindakan perbaikan } \\
\text { terhadap masalah atau } \\
\text { penyimpangan }\end{array}$ & Bukti \\
& $\begin{array}{l}\text { Pelatihan kompetensi } \\
\text { pegawai }\end{array}$ & LAKIP \\
2 & $\begin{array}{l}\text { Dokumentasi hasil } \\
\text { kinerja sumber daya } \\
\text { Evaluasi kinerja } \\
\text { manajemen sumber } \\
\text { daya }\end{array}$ & LAKIP \\
4 & $\begin{array}{l}\text { Evaluasi resiko } \\
\text { tindakan } \\
\text { penyimpangan }\end{array}$ & LAKIP \\
5 & & \\
\hline \hline
\end{tabular}

Pada Tabel 5. terdapat dokumen yang tidak terpenuhi untuk pelatihan kompetensi pegawai, dimana sebenarnya telah dilakukan akan tetapi hanya diperuntukan kepada pegawai yang berstatus PNS sedangkan pegawai NonPNS mendominasi jumlahnya pada DISKOMINFO selain itu, tidak adanya dokumentasi dari pelatihan yang telah dilakukan. Evaluasi resiko tindakan penyimpangan yang belum dilakukan karena tindakan yang dilakukan hanya jika ada permasalahan.

Tabel 6. GWP \& Process Definition

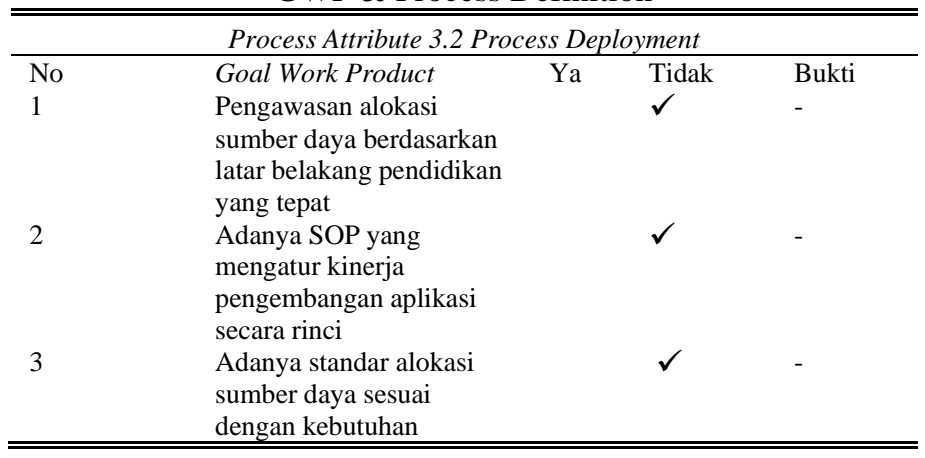

Pada Tabel 6. belum terpenuhi semua dokumen yang berkaitan dengan indikator yang telah ditetapkan. 
2) MEAO1 Monitor Evaluate and Assess Performance and Conformance

Berikut merupakan tabel process attribute level pada level 2 Manage:

Tabel 7.

GWP \& Performance Management

\begin{tabular}{|c|c|c|c|c|}
\hline \multicolumn{5}{|c|}{ Process Attribute 2.1 Performance Management } \\
\hline No & Goal Work Product & Ya & Tidak & Bukti \\
\hline 1 & $\begin{array}{l}\text { Identifikasi kebutuhan } \\
\text { pada pengembangan } \\
\text { aplikasi }\end{array}$ & $\checkmark$ & & $\begin{array}{l}\text { Kedudukan, Fungsi } \\
\text { dan tugas } \\
\text { DISKOMINFO }\end{array}$ \\
\hline 2 & $\begin{array}{l}\text { Identifikasi target } \\
\text { pada pengembangan } \\
\text { aplikasi }\end{array}$ & $\checkmark$ & & Rencana Kegiatan \\
\hline 3 & $\begin{array}{l}\text { Identifikasi data } \\
\text { aplikasi }\end{array}$ & $\checkmark$ & & Daftar Aplikasi \\
\hline 4 & $\begin{array}{l}\text { Identifikasi rencana, } \\
\text { peluang dan resiko } \\
\text { pengembangan } \\
\text { aplikasi }\end{array}$ & $\checkmark$ & & Rencana Kegiatan \\
\hline 5 & $\begin{array}{l}\text { Identifikasi masalah } \\
\text { atau tindakan } \\
\text { penyimpangan pada } \\
\text { pengembangan } \\
\text { aplikasi }\end{array}$ & & $\checkmark$ & - \\
\hline
\end{tabular}

Pada Tabel 7. terdapat dokumen yang tidak terpenuhi untuk identifikasi masalah atau tindakan penyimpangan pada pengembangan aplikasi karena tindakan penyimpangan yang belum dilakukan karena tindakan yang dilakukan hanya jika ada permasalahan.

Tabel 8.

GWP \& Process performance

\begin{tabular}{|c|c|c|c|}
\hline \multicolumn{4}{|c|}{ Process Attribute 2.2 Work Product management } \\
\hline No & Goal Work Product & Ya $\quad$ Tidak & Bukti \\
\hline 1 & $\begin{array}{l}\text { Tujuan \& cakupan } \\
\text { pengembangan aplikasi }\end{array}$ & $\checkmark$ & $\begin{array}{l}\text { PERBUB No. } \\
57 \text { Tahun } \\
2016\end{array}$ \\
\hline 2 & $\begin{array}{l}\text { Pemantauan target } \\
\text { kinerja pengembangan } \\
\text { aplikasi }\end{array}$ & $\checkmark$ & LAKIP \\
\hline 3 & $\begin{array}{l}\text { Monitoring aplikasi } \\
\text { berjalan }\end{array}$ & $\checkmark$ & Data Aplikasi \\
\hline 4 & $\begin{array}{l}\text { Rencana sosialisasi } \\
\text { terkait koordinasi antar } \\
\text { dinas dalam } \\
\text { pengembangan aplikasi }\end{array}$ & $\checkmark$ & Rencana Kerja \\
\hline
\end{tabular}

Berikut merupakan tabel process attribute level pada level 3 Established Process:
Tabel 9.

GWP \& Process Definition

\begin{tabular}{|c|c|c|c|c|}
\hline \multicolumn{5}{|c|}{ Process Attribute 3.1 Process Definition } \\
\hline No & Goal Work Product & $\mathrm{Ya}$ & Tidak & Bukti \\
\hline 1 & $\begin{array}{l}\text { Pengumpulan data } \\
\text { pengembangan } \\
\text { aplikasi }\end{array}$ & $\checkmark$ & & $\begin{array}{l}\text { Data } \\
\text { Aplikasi }\end{array}$ \\
\hline 2 & $\begin{array}{l}\text { Analisis laporan } \\
\text { kinerja }\end{array}$ & $\checkmark$ & & LAKIP \\
\hline 3 & $\begin{array}{l}\text { Dokumentasi } \\
\text { pengembangan } \\
\text { Aplikasi }\end{array}$ & & $\checkmark$ & - \\
\hline 4 & $\begin{array}{l}\text { Rekomendasi } \\
\text { perbaikan kinerja }\end{array}$ & $\checkmark$ & & LAKIP \\
\hline 5 & $\begin{array}{l}\text { Penelusuran masalah } \\
\text { atau tindakan } \\
\text { penyimpangan }\end{array}$ & & $\checkmark$ & - \\
\hline 6 & $\begin{array}{l}\text { Sosialisasi } \\
\text { koordinasi antar } \\
\text { dinas pengembangan } \\
\text { aplikasi dan data }\end{array}$ & $\checkmark$ & & $\begin{array}{l}\text { Surat } \\
\text { Edaran }\end{array}$ \\
\hline
\end{tabular}

Pada Tabel 9. terdapat dokumen yang tidak terpenuhi untuk dokumentasi pengembangan Aplikasi karena kurangnya informasi yang didapat dari berbagai dinas terkait aplikasi yang dikembangkan dan belum atau tidak dilaporkan. Penelusuran masalah atau tindakan penyimpangan dilakukan karena tindakan yang dilakukan hanya jika ada permasalahan.

Tabel 10.

GWP \& Work Product Management

\begin{tabular}{|c|c|c|c|c|}
\hline \multicolumn{5}{|c|}{ Process Attribute 3.2 Process Deployment } \\
\hline No & Goal Work Product & $\mathrm{Ya}$ & Tidak & Bukti \\
\hline 1 & $\begin{array}{l}\text { Alur atau prosedur } \\
\text { proses } \\
\text { pengembangan } \\
\text { aplikasi }\end{array}$ & & $\checkmark$ & - \\
\hline 2 & $\begin{array}{l}\text { Aturan terkait } \\
\text { koordinasi terkait } \\
\text { pengembangan } \\
\text { aplikasi dan data }\end{array}$ & $\checkmark$ & & $\begin{array}{l}\text { PERBUB } \\
\text { No } 11 \\
\text { Tahun } \\
2015 \\
\text { Pasal } 7 \\
\text { ayat } 3 \\
\text { dan } 4\end{array}$ \\
\hline 3 & $\begin{array}{l}\text { Evaluasi dan } \\
\text { penilaian terkait } \\
\text { kegiatan } \\
\text { pengembangan } \\
\text { aplikasi dan data }\end{array}$ & & $\checkmark$ & - \\
\hline
\end{tabular}


Pada Tabel 10. belum terpenuhi untuk alur atau prosedur proses pengembangan aplikasi yang belum ada sehingga belum adanya panduan atau arahan yang jelas terkait bagaimana pengembangan aplikasi dan data ini dilakukan. Selain itu, evaluasi dan penilaian terkait kegiatan pengembangan aplikasi dan data dimana terbatas pada evaluasi rapat yang dilakukan dan belum adanya dokumentasi khusus terkait pengembangan aplikasi dan data pada DISKOMINFO Kabupaten Bogor.

\section{G. Reporting the Result}

Berdasarkan hasil wawancara diketahui bahwa tingkat kematangan yang diharapkan (expected level) dan dari hasil perhitungan diketahui tingkat kematangan yang ada pada DISKOMINFO Kabupaten Bogor saat ini (current level). Berikut merupakan gambaran analisis gap tingkat kematangan pada proses EDM04 Ensure Resource Optimization dan MEA01 Monitor Evaluate and Assess Performance and Conformance.

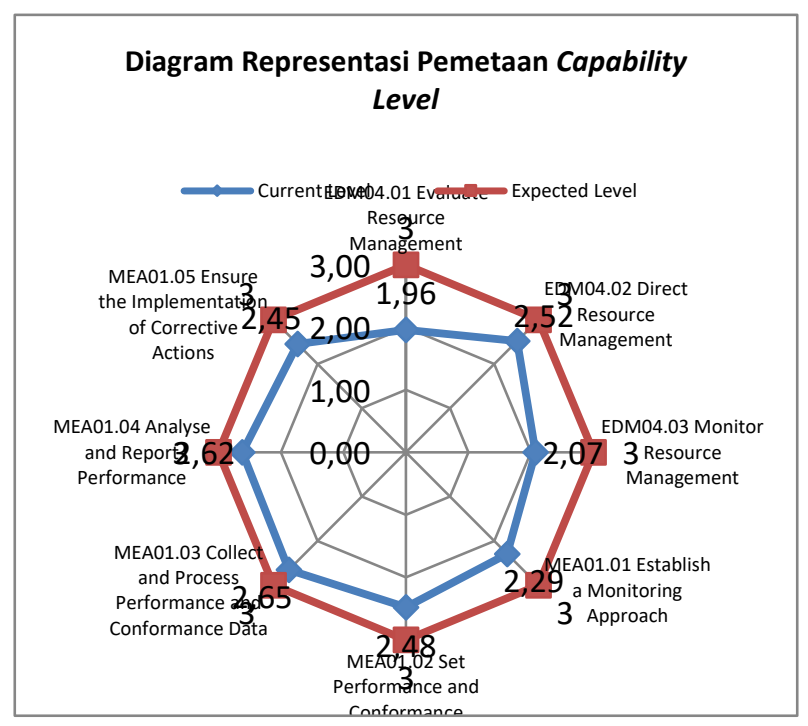

Gambar 2. Representasi Pemetaan Capability Level

Dari gambar 2 diatas diketahui bahwa current level (as is) berada pada level 2 (managed process) dan expected level (to be) berada pada level 3 (establish process) baik pada proses EDM04 maupun proses MEA01. Dimana proses dalam meraih tujuan yang telah ditentukan sudah direncanakan, dipantau dan disesuaikan dengan baik walaupun dalam pelaksanaanya belum dilakukan secara sempurna. DISKOMINFO Kabupaten Bogor telah merencanakan kebijakan untuk meningkatkan kompetensi pegawai serta melakukan koordinasi dan monitoring terhadap pembuatan atau pengembangan sistem yang ada di lingkungan Kabupaten Bogor. Berdasarkan hasil perhitungan questioner dan observasi yang dilakukan, maka didapatkan nilai capability level 2,48 pada DISKOMINFO Kabupaten Bogor khususnya Seksi Pengembangan Aplikasi dan Data berada pada level dua.
1) Rekomendasi EDM04 Ensure Resource Optimization berdasarkan aktivitas ISO/IEC 38500

a. Responsibility (Tanggung Jawab)

Seksi Pengembangan Aplikasi dan Data (PAD) DISKOMINFO Kabupaten Bogor mengevaluasi, mengarahkan dan memonitor kompetensi pegawai yang menerima tanggung jawab serta menetapkan alokasi sumber daya dalam melakukan pengembangan aplikasi sesuai dengan kemampuan yang dimiliki, mengevaluasi, mengarahkan dan memonitor rencana kerja yang dirancang agar dilaksanakan dengan baik, mulai dari membuat strategi yang harus dilakukan hingga laporan yang diselesaikan tepat waktu dan mengevaluasi, mengarahkan dan memonitor target kinerja yang telah dicapai sesuai dengan tanggung jawab yang diberikan.

b. Strategy (Strategi)

Seksi PAD DISKOMINFO Kabupaten Bogor mengevaluasi, mengarahkan dan memonitor rancangan kebijakan dan rencana pemanfaatan nilai TI sesuai dengan kebutuhan dan tujuan yang ditetapkan, mengevaluasi, mengarahkan dan memonitor pencapaian tujuan dengan sumber daya yang direncanakan serta membuat alur yang jelas terkait pengembangan aplikasi yang akan dibuat serta disosialisasikan dengan baik kepada SKPD Kabupaten Bogor. Selain itu, mengevaluasi, mengarahkan, memonitor dan memastikan kemampuan sumber daya TI yang memadai dengan mengadakan pelatihan yang terencana dan menyeluruh kepada pegawai DISKOMINFO Kabupaten Bogor khususnya pada Seksi Pengembangan Aplikasi dan Data.

c. Acqusition (Perolehan)

Seksi PAD DISKOMINFO Kabupaten Bogor mengevaluasi, mengarahkan dan memonitor setiap project pengembangan aplikasi yang akan dilakukan baik terkait biaya yang dikeluarkan hingga kemungkinan resiko yang akan terjadi baik dari investasi hingga penggunaan teknologi informasi yang sesuai kebutuhan.

d. Performance (Kinerja)

Seksi PAD DISKOMINFO Kabupaten Bogor mengevaluasi, mengarahkan, memonitor Satuan Kerja Perangkat Daerah (SKPD) atau instansi yang akan mengembangkan aplikasi untuk menentukan prioritas dan batasan pada pengembangan aplikasi yang akan dilakukan. Selain itu, memastikan kebutuhan sumber daya TI yang memadai dalam melakukan pengembangan aplikasi sesuai dengan kebutuhan serta mengevaluasi efektifitas dari keputusan yang dibuat dalam penggunaan teknologi informasi.

e. Conformance (Kesesuaian)

Seksi PAD DISKOMINFO Kabupaten Bogor mengarahkan, mengevaluasi dan memonitor kegiatan pengembangan aplikasi dilakukan sesuai dengan kebijakan dan aturan yang berlaku, atau tidak menyalahi aturan yang ada. Kemudian, memastikan kepatuhan tehadap perjanjian yang telah disepakati baik dari 
ketepatan waktu dan kelengkapan laporan terkait pengembangan aplikasi yang dilakukan, memantau agar proses pengembangan aplikasi disesuaikan dengan prosedur yang ada serta mematuhi kebijakan internal yang dimiliki oleh DISKOMINFO Kabupaten Bogor.

f. Human Behaviour (Perilaku Manusia)

Seksi PAD DISKOMINFO Kabupaten Bogor mengevaluasi, mengarahkan dan memonitor kegiatan pelatihan yang dilakukan agar pengetahuan yang disampaikan relevan baik terkait kompetensi terkait teknologi informasi hingga tanggung jawab dan pelaporan yang sesuai dengan aturan yang berlaku. Kemudian, mengidentifikasi dan mengevaluasi perilaku penyimpangan pegawai dalam kegiatan TI.

2) Rekomendasi MEA01 Monitor Evaaluate and Assess Performance and Conformance berdasarkan aktivitas ISO/IEC 38500

a. Responsibility (Tanggung Jawab)

Seksi Pengembangan Aplikasi dan Data (PAD) DISKOMINFO Kabupaten Bogor merencanakan, mengevaluasi dan memonitor proses pengembangan aplikasi yang dituangkan dalam bentuk kebijakan atau SOP yang jelas, kemudian mensosialisasikannya dengan baik serta mengalokasikan sumber daya yang tepat dalam proses kegiatannya. Kemudian, menetapkan tanggung jawab sesuai dengan kemampuan yang dimiliki baik dalam hal pengumpulan informasi, dokumentasi kegiatan pengembangan aplikasi hingga identifikasi tindakan penyimpangan dan tindakan perbaikannya.

b. Strategy (Strategi)

Seksi PAD DISKOMINFO Kabupaten Bogor mengevaluasi, mengarahkan dan memonitor kegiatan sosialisasi terkait pengembangan aplikasi secara menyeluruh kepada SKDP yang ada pada lingkungan Kabupaten Bogor. Kemudian, mengadakan sosialisasi lebih lanjut terkait prosedur pengembangan aplikasi dan data yang dapat dilakukan melalui internet, surat dan lainnya kemudian, mengevaluasi, mengarahkan dan memonitor hasil dari setiap pengembangan aplikasi untuk dijadikan tolok ukur atau penilaian terkait keberhasilan pengembangan aplikasi. Selain itu, memastikan tercapainya tujuan kinerja yang berupa koordinasi dan memonitor pengembangan aplikasi sesuai dengan yang diharapkan dan pencatatan terhadap segala bentuk kegiatan pengembangan aplikasi.

c. Acquisition (Perolehan)

Seksi PAD DISKOMINFO Kabupaten Bogor mengevaluasi, mengarahkan dan memonitor investasi yang diberikan sesuai dengan hasil yang diharapkan dalam mendukung kebutuhan SKDP dalam mengembangkan aplikasi yang akan dibuat, memastikan pemahaman terkait kebutuhan yang harus dipenuhi terkait pengembangan aplikasi baik dengan berbagai opsi dengan penawaran TI terkait biaya dan resiko terkait pengembangan aplikasi serta memantau investasi yang diberikan agar sesuai dengan kemampuan yang diharapkan. Kemudian, memberikan informasi yang disampaikan sesuai dengan apa yang terjadi di lapangan kepada pimpinan.

\section{d. Performance (Kinerja)}

Seksi PAD DISKOMINFO Kabupaten Bogor memberikan informasi dan kegiatan sosialisasi terkait informasi pengembangan sistem lebih lanjut baik terkait prosedur, kedudukan DISKOMINFO dan lainnya agar SKPD yang akan membuat atau mengembangkan sistem dapat berkoordinasi dengan DISKOMINFO sesuai dengan peraturan yang berlaku terkait pengembangan aplikasi, menganalisa proposal pengembangan aplikasi yang akan dilakukan baik dari identifikasi kebutuhan, biaya hingga kemungkinan resikomuncul serta mengevaluasi, mengarahkan dan memonitor sumber daya yang dibutuhkan penggunaan TI secara efisien. Selain itu, melakukan dokumentasi di setiap kegiatan pengembangan aplikasi agar laporan dapat dibuat secara akurat dan tepat waktu.

e. Conformance (Kesesuaian)

Seksi PAD DISKOMINFO Kabupaten Bogor mengevaluasi, mengarahkan dan memonitor kebijakan atau perjanjian yang ditetapkan tidak menyalahi aturan yang berlaku, mengevaluasi kepatuhan terhadap prosedur pengembangan aplikasi baik dari perencanaan hingga pelaporan kegiatan pengembangan aplikasi. Selain itu, memastikan sejauh mana kegiatan perbaikan terhadap penyimpangan atau masalah yang timbul dapat dilakukan secara tepat tanpa harus melanggar aturan atau regulasi yang berlaku baik dari undang-undang atau peraturan yang berlaku di DISKOMINFO Kabupaten Bogor.

f. Human Behaviour (Perilaku Manusia)

Seksi PAD DISKOMINFO Kabupaten Bogor mengevaluasi, mengarahkan dan memonitor praktik kinerja yang sesuai dan konsisten sesuai dengan ketentuan yang berlaku dengan prosedur yang ditetapkan baik dalam ketepatan waktu, tercapainya target hingga hasil yang dilaporkan kepada stakeholder.

\section{KESIMPULAN}

Hasil evaluasi dengan pendekatan capability level pada COBIT 5 pada Seksi Pengembangan Aplikasi dan Data berada pada level 2 managed process dengan nilai capability level 2,38 (Managed Process) untuk proses EDM04 ensure resource optimistion dan MEA01 monitor evaluate and assess performance and conformance. Sedangkan target capability level yang diharapkan adalah 3,00 sehingga terdapat Gap sebesar 0,62 untuk bisa mencapai target yang diharapkan.

Pada EDM04 ensure resource optimization berada pada level 2 managed dengan nilai capability level 2,13 (Managed Process) yang berarti adanya proses aktivitas dari identifikasi 
kompetensi pegawai pada DISKOMINFO yang direncanakan, dimonitor dan disesuaikan untuk meningkatkan kinerja dari pegawai akan tetapi belum diimplementasikan secara sempurna sehingga direkomendasikan untuk melakukan pelatihan teknologi informasi (TI) dan membuat modul sharing knowledge kepada pegawai NonPNS khususnya yang bertanggung jawab pada kegiatan pengembangan aplikasi dan data.

Pada MEA01 monitor evaluate and assess performance and conformance berada pada level 2 managed process dengan nilai capability level 2,51 (Process Performance) yang berarti adanya proses aktivitas dari monitoring sistem yang berjalan serta koordinasi antar dinas yang direncanakan, dimonitor dan disesuaikan dalam pengembangan sistem (aplikasi) akan tetapi belum diimplementasikan secara sempurna sehingga disarankan untuk melakukan sosialisasi lebih lanjut terkait pengembangan aplikasi yang telah dan akan dilakukan oleh dinas lain agar kegiatan pengembangan sistem dapat dikoordinasikan dan dimonitor dengan baik. Selain itu, membuat SOP terkait alur pembuatan atau pengembangan aplikasi yang jelas, membuat daftar log pengembangan aplikasi dan data kegiatan tersebut dapat dimonitor dengan baik sesuai dengan aturan yang berlaku pada PERBUB No.11 Tahun 2015.

\section{REFERENSI}

[1] H. Bin-Abbas and S. H. Bakry, "Assessment of IT governance in organizations: A simple integrated approach," Computers in Human Behavior, vol. 32, pp. 261-267, 2014/03/01/ 2014.

[2] Y. Lulu, "Analisa Teori IT Governance Menggunakan COBIT 5," Jurnal Teknik Elektro dan Komputer, pp. 1(1), 99-106., 2013.

[3] G. Waluyan and A. D. Manuputty, "Evaluasi Kinerja Tata Kelola TI
Terhadap Penerapan Sistem Informasi Starclick Framework COBIT 5 (Studi Kasus: PT. Telekomunikasi Indonesia, Tbk Semarang)," Jurnal Teknologi dan Sistem Informasi, pp. 2(3), 157-1, 2016.

[4] G. Waluyan and A. D. Manuputty, "Evaluasi Kinerja Tata Kelola TI Terhadap Penerapan Sistem Informasi Starclick Framework COBIT 5 (Studi Kasus: PT. Telekomunikasi Indonesia, Tbk Semarang)," Jurnal Teknologi dan Sistem Informasi, vol. 2, no. 3, pp. 157-166, 2016.

[5] F. R. P. Suwarno, "Evaluasi tata kelola teknologi informasi menggunakan framework cobit 5 fokus pada proses manage relationship (APO08): studi kasus PT Oto Multiartha," 2014.

[6] A. Chaudhuri, "Enabling effective IT governance Leveraging ISOIEC 385002008 and COBIT to achieve business-IT alignment," Edpacs, pp. 1-18., 2011.

[7] G. C. Wiedenhoft and E. M. Luciano, "Information Technology Governance In Public Organizations: identifying mechanisms that meet its goals while respecting principles," vol. 14, no. 1, pp. 69-87, 2017.

[8] S. I. Farida, F. Fitroh, and E. Rahajeng, "Usulan model tata kelola teknologi informasi pada domain monitor, evaluate and assess dengan metode framework cobit 5," Studia Informatika: Jurnal Sistem Informasi, vol. 7, no. 2, 2014.

[9] I. E. Kaban "Tata Kelola Teknologi Informasi (IT Governance)," CommIT (Communication and Information Technology) Journal, pp. 3(1), 1-5, 2009.

[10] I. I. 38500, ISO/IEC 38500: Corporate Governance of Information. Swizerland: International Standard, 2008.

[11] P. N. Blanchard and J. W. Thacker, Effective Training, Systems, Strategies, and Practices. New Jersey: Pearson, Prentice Hal, 2007.

[12] G. Parry, M. John , and T. Celine "Lean competence integration of theories in operations management practice," Supply chain management An international journal, 1998.

[13] G. R. Terry, Principles of Management (Prinsip-Prinsip Manajemen). Interpreting Smith, J., $J$ (2008). Jakarta Earth Literacy: Interpreting Smith, J, 2008.

[14] ISACA, COBIT. 5 A Business Framework for the Governance and Management of Enterprise IT. ISACA, 2013.

[15] W. Widhiarso, SKLO: Program Ananlisis Skala Guttman. Yogyakarta: Universitas Gajah Mada, 2011. 